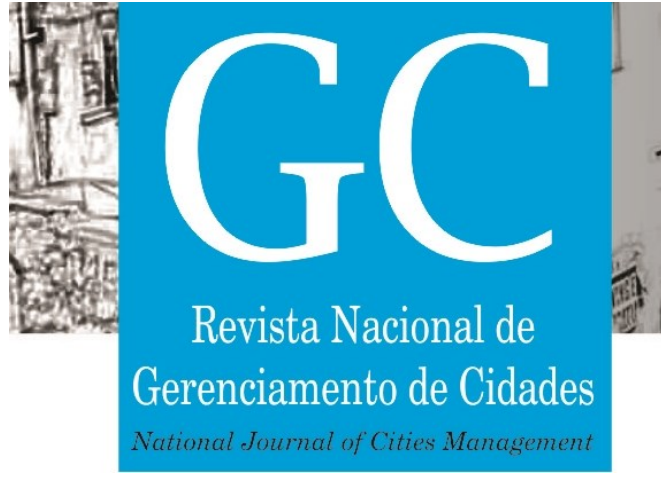

目

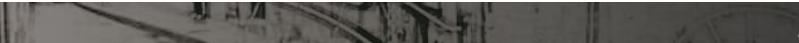

ISSN 2318-8472

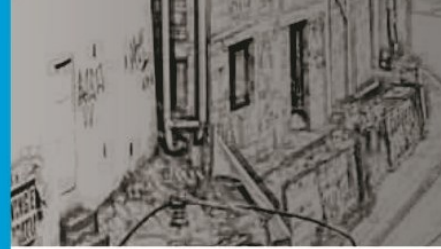
v. 04, n. 25, 2016

\title{
RELAÇÕES ENTRE LINHAS FÉRREAS E VAZIOS URBANOS
}

\author{
Relationship between rail system and residual areas
}

Clarice Eckert Zignani

Mestranda no Programa de Pós-Graduação em Arquitetura e Urbanismo, UNISINOS, Brasil

projetos.ce@terra.com.br

André de Souza Silva

Professor Doutor em Planejamento Urbano Regional, UNISINOS, Brasil silandre@unisinos.br 


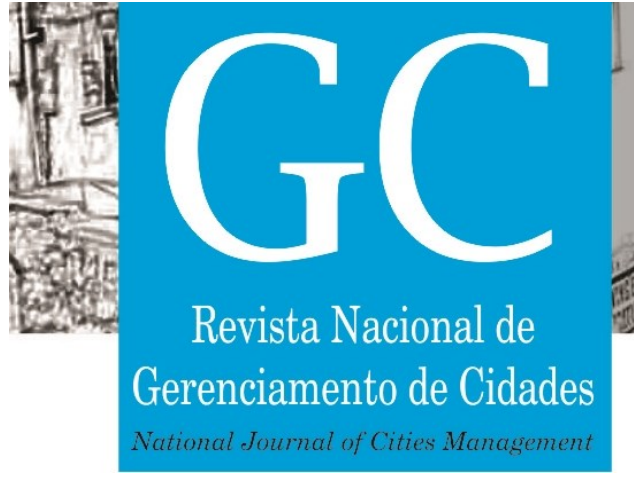

ISSN 2318-8472

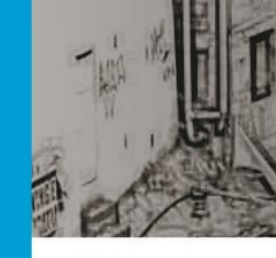

\title{
Resumo
}

Analisar a relação existente entre o nível de integração do sistema de vias, linhas férreas e, a ocorrência de vazios urbanos na cidade de Novo Hamburgo, tomada como estudo de caso, é o objetivo que se apresenta. A análise sintática dos mapas de diferentes períodos morfológicos da cidade possibilitou entender o quanto tais intervenções alteraram significativamente a mobilidade urbana. Os diferentes cenários da formação e transformação da morfologia da cidade em termos de seu sistema configuracional de vias demonstraram que áreas residuais ao longo de linhas férreas estão diretamente relacionadas ao nível de acessibilidade urbana.

Palavras-chave: cidade; sintaxe especial; acessibilidade; linha férrea

\begin{abstract}
This paper aims to analyze the relationship between the level of integration of the road and rail systems and the occurrence of urban voids in the city of Novo Hamburgo, which is our case study. The synthetical analysis of the maps of different morphological phases of the city allowed us to understand how much such interventions significantly altered urban mobility. The different scenarios of formation and transformation of the city's morphology in terms of its configurational road system showed that residual areas along the railway are directly related to the level of urban accessibility.
\end{abstract}

Key-words: city; space syntax; accessibility; rail system 


\section{INTRODUÇÃO}

Esse artigo versa sobre a relação entre o estabelecimento de uma linha férrea no meio urbano e as conexões e fluxos do sistema de vias onde o mesmo está inserido. Mais específicamente, trata de analisar o caso da cidade de Novo Hamburgo, onde este tipo de transporte coletivo foi inserido em dois momentos históricos distintos de sua expansão territorial. Para a construção desse entendimento, faz-se necessário analisar o sistema de vias da cidade em três períodos de tempo distintos: 1948 (com a linha férrea antiga ainda em funcionamento), 1990 (após o encerramento das primeiras atividades ferroviárias e antes da inauguração da linha férrea nova) e 2016 (período atual, com a linha férrea da Trensurb em funcionamento).

O problema de pesquisa, portanto, centra-se na investigação acerca da mudança de trajeto da linha férrea nova em relação à descontinuada em 1964, buscando entender se essa mudança corroborou para a formação das áreas residuais, bem como com o perfil de deslocamento populacional. A hipótese mais provável para os vazios urbanos gerados é a de que a mudança de percurso da linha férrea não tenha fomentado o desenvolvimento de novas atividades, visto que o sistema de vias e de comércio já estava consolidado pelo traçado anterior e que a acessibilidade às demais áreas da cidade não foi alterada com a chegada do trem.

Para descobrir o quanto esta mudança de traçado influenciou na mobilidade urbana e na criação de áreas sem uso no entorno do trem, utilizou-se como método a técnica de análise sintática por meio da construção de mapa axial do sistema de vias (Sintaxe Espacial, HILLIER e HANSON, 1984). A construção do mapa sintático tem como base o desenho de linhas axiais sobre o sistema viário de determinada cidade, conectando-se uns aos outros, através de sobreposição. A conectividade de um sistema urbano pode ser medida através do número de linhas que intercepta cada traço (CARMO, RAIA JÚNIOR \& NOGUEIRA, 2013, s.p.). Desse modo, pode-se entender que esse método de análise urbana mede as possibilidades de deslocamento (RIBEIRO \& MEDEIROS, 2012, p.126). Na formação do mapa de linhas axiais o nível de integração das vias (acessibilidade sintática) com a cidade é representado numa escala de cores, onde o trajeto com maior possibilidade de conexão aparece na cor vermelha, seguido pela cor laranja, verde e azul representando a menos conectada.

Embora as análises de acessibilidade e mobilidade urbana estejam diretamente relacionados com os fluxos existentes na cidade de Novo hamburgo, a pesquisa está voltada à ocupação urbana, e na tentativa de descobrir se existe alguma relação entre a conectividade da avenida que o trem percorre na cidade e o desenvolvimento comercial e econômico ao longo da linha férrea construída pela Trensurb. Além disso, busca-se entender o fator atrativo para a população local, em termos de interações sociais que poderia ocorrer nos espaços existentes. Assim, de modo complementar foram analisados conjuntamente o (i) meio de transporte e o trajeto mais adequado para o deslocamento entre as cidades de São Leopoldo e Novo Hamburgo; a (ii) forma mais adequada de chegar até o shopping Bourbon em Novo Hamburgo (observa-se que o estabelecimento está situado em frente à última estação da Trensurb na Cidade); e (iii) a forma de deslocamento utilizada entre a moradia e o trabalho. 


\section{CONDIÇÃO RELACIONAL ENTRE A ACESSIBILIDADE E OS VAZIOS URBANOS}

Embora tenham tido seu período áureo, o aumento da presença de automóveis contribuiu, com o passar dos anos, para o sucateamento das linhas férreas brasileiras, em específico as de Novo Hamburgo. Um exemplo desse acontecimento foi o ocorido com o transporte hamburguense, que funcionou até 1964 (BRAUN, 2010, p.80). Nessa época, as rodovias intermunicipais estavam em bom estado, e muitas linhas de ônibus foram introduzidas no transporte público hamburguense, ocasionando a extinção do trajeto ferroviário entre as cidades de Porto Alegre e Taquara (SELBACH, 2006, p. 18-19).

A construção da BR-116 em 1942, denominada Getúlio Vargas na época de sua inauguração, modificou a configuração urbana de Novo Hamburgo. A expansão do sistema de vias iniciada no atual bairo de Hamburgo Velho (centro histórico da época) se intensificou em direção à rodovia e à estrada de ferro que cortava a cidade, favorecendo o aperecimento do novo polo comercial e de serviços. Criou-se então um centro para a cidade, tal qual permanence até os dias de hoje, sem planejamento urbano ou oferta de redes de serviços.

Somente em 2014 os trens voltaram a circular em Novo Hamburgo, após a inauguração da linha atual, operada pela Trensurb, e cuja obra de infraestrutura para o funcionamento do transporte na malha urbana consolidada produziu vazios urbanos ao longo de todo o percurso ferroviário, embaixo da estrutura edificada. Por vazios urbanos entende-se as áreas urbanas carentes de uma função específica, resultantes do processo de urbanização. A expressão ainda poderia ser associada às palavras "vacante, vago, abandonado, desocupado e subutilizado" (BORDE, 2003, p.1-3). Assim, relaciona-se os espaços ociosos ao longo da linha do trem em Novo Hamburgo ao termo "vazios urbanos", por não terem ocupação efetiva e não se caracterizarem como ponto de encontro entre pessoas nem como local para desenvolvimento de atividades.

Há diversas hipóteses que levaram esses espaços a se tornarem ociosos. Uma delas diz respeito às atividades desenvolvidas ou ausentes ao longo do percurso. Os primeiros sinais de áreas desocupadas provenientes da expansão do sistema de vias após a construção da BR 116, e em decorrência de uma ausência de planejamento, poderiam se aplicar também ao occorido a partir da implementação da linha férrea em 2014. Do mesmo modo que nos anos que se seguiram a 1942, não houve, por parte da Trensurb ou do Poder Público, um projeto urbanístico capaz de discutir quais tipos de edificações seriam necessárias atrair à area, para uma intervenção bem sucedida, em termos de fluxos e permanência de pessoas.

Parte das obras acordadas de infraestrutura urbana no entorno do trem, tais como pavimentações de passeios públicos, ciclovia de dimensões adequadas e interligação com demais transportes da cidade não foram executadas. Se, de acordo com Vasconcellos, o planejamento da mobilidade define a forma como a estrutura viária de uma cidade será utilizada por pessoas e veículos (VASCONCELOS, 2012,p.144), pode-se entender que a ausência dessa infraestrutura contribui para que a via por onde o trem passa em Novo Hamburgo - início da 


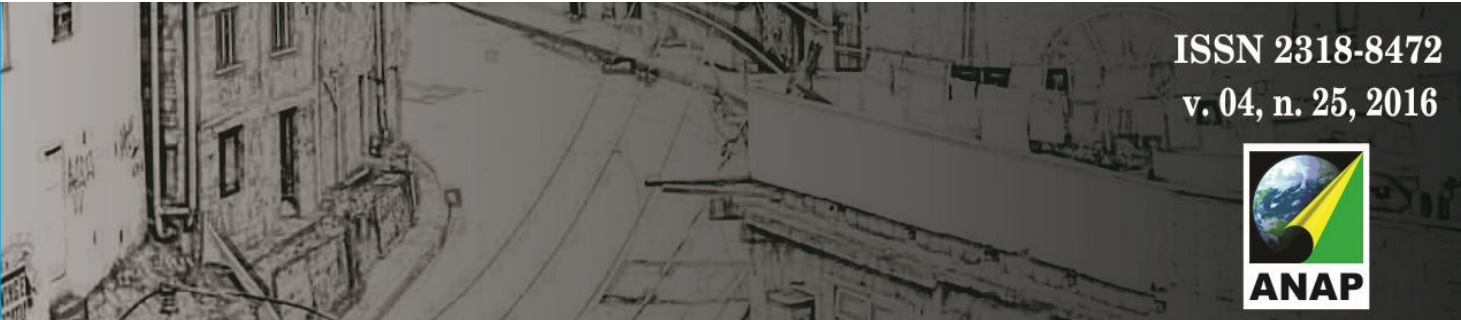

Gerenciamento de Cidades

avenida Primeiro de Março e parte da rua Nações Unidas - não seja utilizada como uma das principais rotas de deslocamento para as pessoas. Nesse contexto, é possível considerar que, se não há incentivo capaz de fomentar a permanência ou a passagem por determinado local, este torna-se lugar sem uso definido e, portanto, um vazio urbano.

\section{ANÁLISE SINTÁTICA DO SISTEMA DE VIAS DE NOVO HAMBURGO EM TRÊS PERÍODOS DE TEMPO}

A partir do mapa do sitema de vias da cidade de Novo Hamburgo, em diferentes períodos de tempo, foram desenhadas as linhas axiais de modo a embasar a análise topológica da acessibilidade sintática. $O$ resultado são imagens do sistema de vias cuja escala de valores cromáticas exibe desde as linhas axiais mais acessíveis (vermelho) até as menos acessíveis (azul) (JALES, 2014, s.p.; FIGUEIREDO,2005, p.5; AGUIAR, 2002, s.p. apud JALES, 2014, s.p.).

Áreas centrais têm sua importância fortalecida pela localização das atividades, porém com a expansão planejada do sistema de vias, novas centralidades surgem e são capazes de concentrar diversas atividades necessárias ao cotidiano das pessoas e para a manutenção do sistema capitalista, tais como comércio, serviços e circulações (de pessoas e mercadorias) (ALVES, 2014, p.112; VARGAS \& CASTILHOS, 2015, p.1-2). Entretanto, em Novo Hamburgo, isso de fato não ocorreu com a chegada do trem a cidade em 2014. Do ponto de vista da análise sintática o centro urbano apresenta-se, geralmente, a partir da aglomeração de diversas linhas axiais em torno da tonalidade vermelha, visto tratar-se do local de maior conectividade com as demais zonas urbanas, i.e. a concentração de linhas axiais mais acessíveis da cidade como um todo. Assim sendo, no periodo de 1948, quando a primeira linha férrea da cidade estava em funcionamento, observa-se que no mapa axial de interação global do sistema de vias há muitas zonas de baixa conectividade com o centro da cidade (Fig. 1). A BR-116 era uma via de baixa conectividade e, portanto, de pouca importância para a mobilidade entre as cidades pela qual passava. Já a Avenida Primeiro de Março (vermelho), tratava-se de uma caminho mais utilizado para deslocamentos. Foi entorno desta avenida que se estabeleceu o centro de Novo Hamburgo, com suas edificações públicas e espaços para lazer. Ainda de acordo com a análise sintática pode-se perceber que a maior conectividade do sistema de vias estava no centro da cidade, e em vias dispostas de forma perpendicular à Avenida, criando uma imagem semelhante à uma cruz. Paradoxalmente, a cidade parecia crescer em direção oposta a BR 116. 


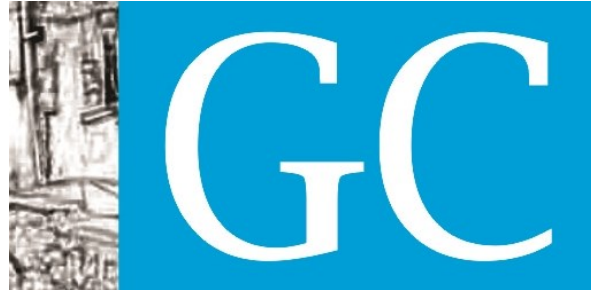

Revista Nacional de

Gerenciamento de Cidades

National Joumal of Cities Management

Figura 1: Mapa axial de Novo Hamburgo em 1948

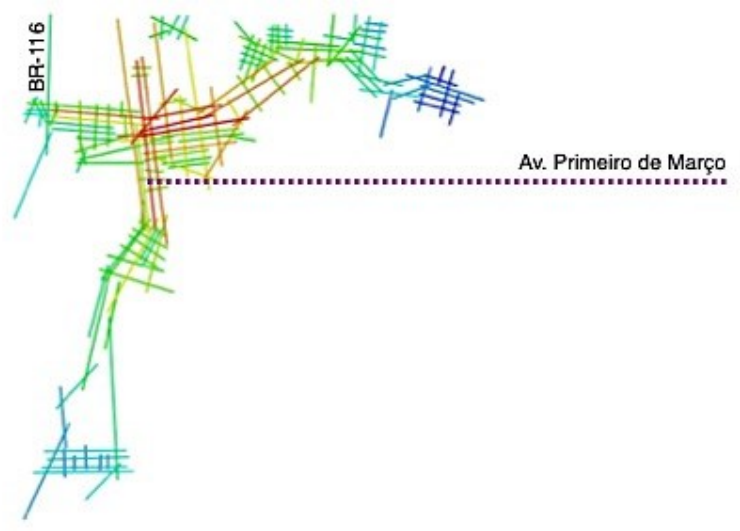

Fonte: original dos autores, 2016

Já o mapa axial de 1990 (Fig. 2), que corresponde ao período entre o encerramento das atividades da antiga linha férrea e a inauguração da nova, é possível notar que a cidade teve seu crescimento de forma circular, ou seja, o sistema de vias foi crescendo entorno do centro.

Figura 2: Mapa axial de Novo Hamburgo em 1990.

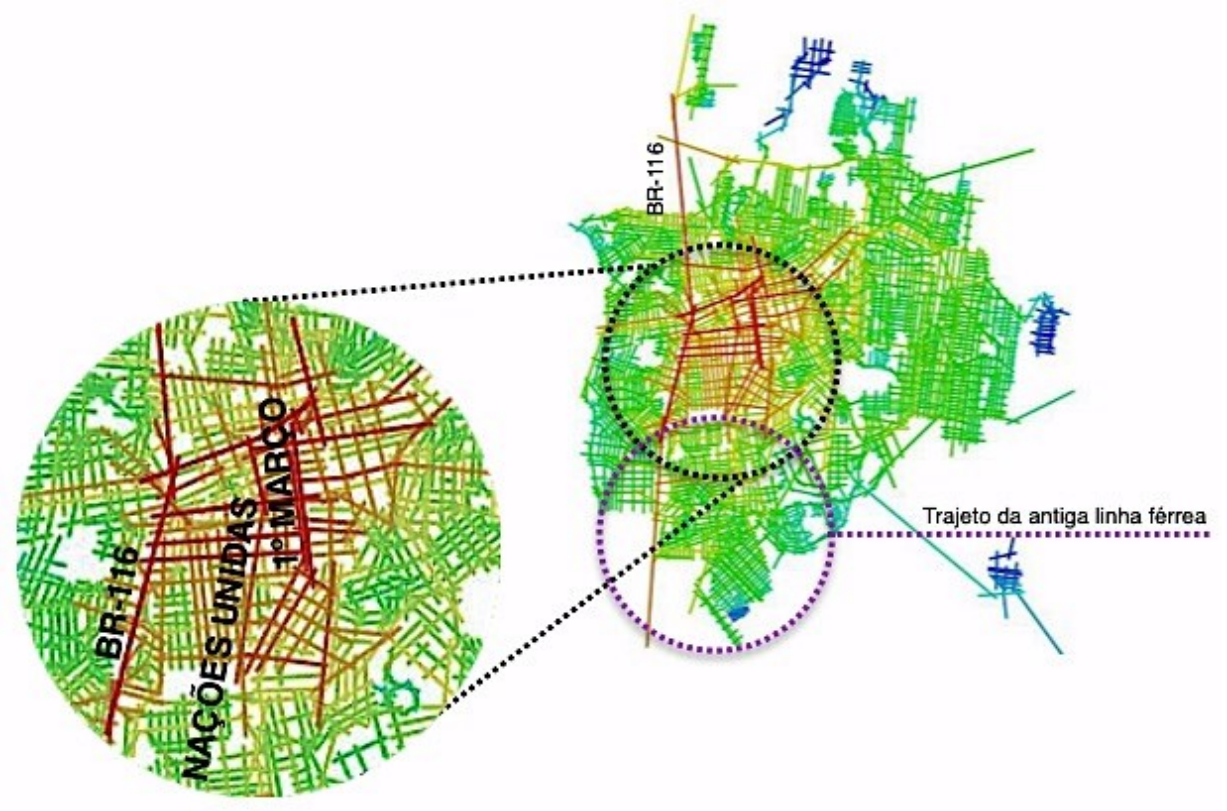

Fonte: original dos autores, 2016 


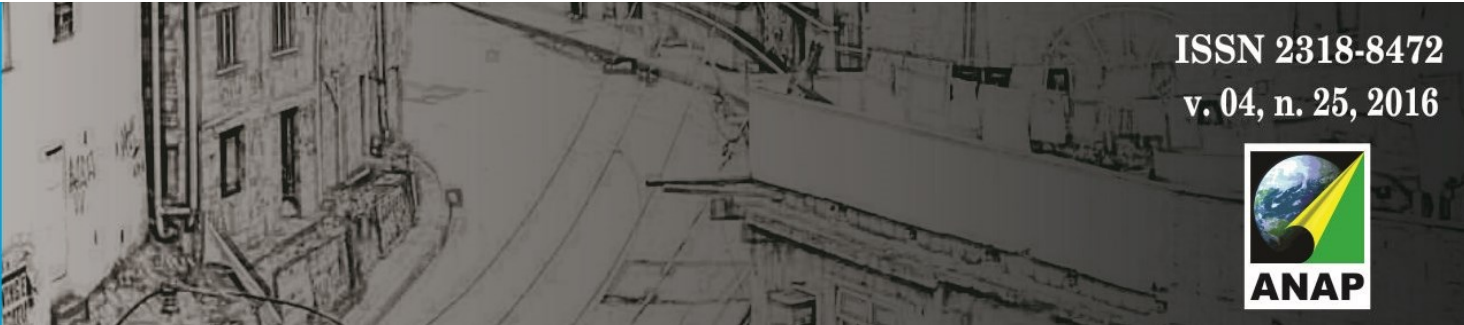

Gerenciamento de Cidades

Observa-se também que a BR-116 passou a ter importância para a acessibilidade e consequente mobilidade urbana a Novo Hamburgo e cidades limítrofes. Além disso, mesmo que estivesse dividindo o sistema de vias não favoreceu o isolamento de nenhuma área no seu entorno.

Já a área central, com maiores possibilidades de acesso e deslocamento, manteve as características apresentadas desde 1948, não sendo criada nova centralidade em aproximadamente quarenta anos de expansão, mesmo que a área territorial tenha aumentado consideravelmente, e de forma circular.

Em 1990 já é possível ver o aparecimento da zona rural da Cidade (Bairro Lomba Grande em torno das linhas axiais de cor azul, no quadrante sul da cidade), interligada à zona urbana. Seria previsível a apresentação de zonas com baixa conectividade no trajeto da linha férrea desativada, visto a descontinuidade desse transporte público, o fortalecimento da rodovia como possibilidade de deslocamento e, o consequente aumento na utilização de automóveis durante o intervalo de tempo entre os dois mapas apresentados. Mesmo que a acessibilidade da Cidade tenha aparentemente melhorado (a partir da criação de novos pontos de conexão internos e com a periferia), percebe-se que a Avenida Primeiro de Março permanece inserida em uma centralidade, e como ponto principal de deslocamento - visto estar representada pela cor vermelha.

No mapa axial de Novo Hamburgo de 2016, pode-se ver o traçado anterior e atual do trem, percorrendo parte da Avenida Primeiro de Março, e estendendo-se sobre a rua Nações Unidas até o shopping da cidade (Fig. 3). Ambas as vias citadas encontram-se inseridas na zona central do sistema de vias, porém caracterizam-se por apresentar boa acessibilidade e conexão com o sistema viário da cidade apenas de seu entorno imediato. Desse modo, o percurso entre a divisa de Novo Hamburgo com a cidade de São Leopoldo permanence pouco conectado ao restante do território - mesmo após a implementação do trem. 
Figura 3: Mapa axial de Novo Hamburgo em 2016.

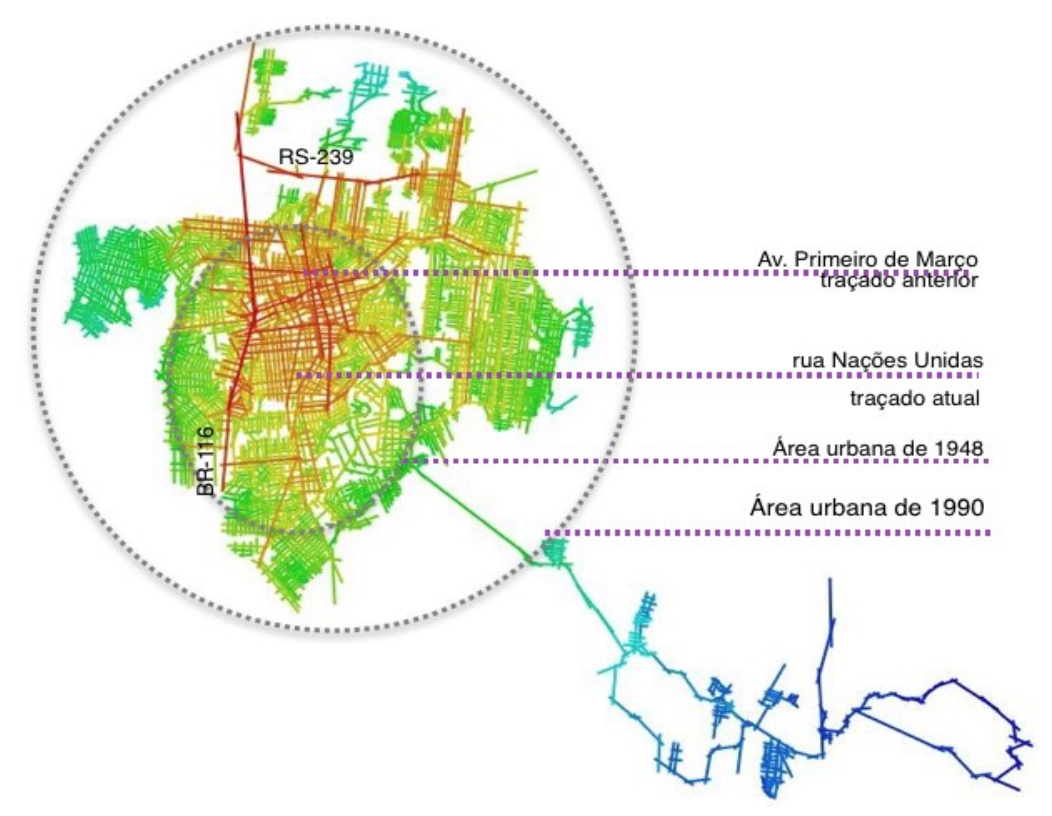

Fonte: original dos autores, 2016

Além disso, percebe-se tanto a expansão da zona rural, mesmo que ainda com pouca ligação à circulação viária da área urbana de Novo Hamburgo, quanto o fortalecimento das ligações entre a zona central com a BR-116 e a RS-239.

O número de linhas axiais que foram desenhadas em cada mapa axial para a construção das imagens aqui apresentadas, podem ser vistas na tabela abaixo (Fig. 4). Interessante foi perceber que apesar de ter aumentado consideravelmente a extensão territorial da Cidade desde 1948, novas centralidades não foram criadas, ou seja, o centro da cidade permaneceu no local de origem (Tab. 1). Esse fato pode ser comprovado visualmente e através do número de linhas axiais formadas.

São entendidas como centralidades os espaços que concentram as mais diversas atividades comerciais e de serviços necessárias à vida cotidiana, e também as chamadas "centralidades vividas", que são os locais onde as relações socioespaciais são vivenciadas (SERPA, 2014, p.104). Esses locais onde a vida cotidiana se realiza são constituídos principalmente pelos espaços públicos que assim tornam-se palco de acontecimentos. 
Figura 4: Sistema de linhas axiais em três períodos de tempo em Novo Hamburgo

\begin{tabular}{|c|c|c|c|}
\hline Ano & 1948 & 1990 & 2016 \\
\hline Número de linhas & 149 & 2038 & 2618 \\
\hline
\end{tabular}

Fonte: original dos autores, 2016

Analisando a conectividade para os três períodos de tempo desse estudo, percebe-se que somente no mapa de 1948 o eixo viário por onde passava a linha férrea, e que passa no centro da cidade aparece representado na cor vermelha, o que indica um índice elevado de integração com o restante do sistema de vias, conforme mapa (Fig. 5). Entende-se que nessa data, a Avenida Primeiro de Março era utilizada como principal rota de deslocamento dentro do perímetro urbano e para fora do mesmo, em direção as cidades vizinhas.

Figura 5: Conectividade em 1948

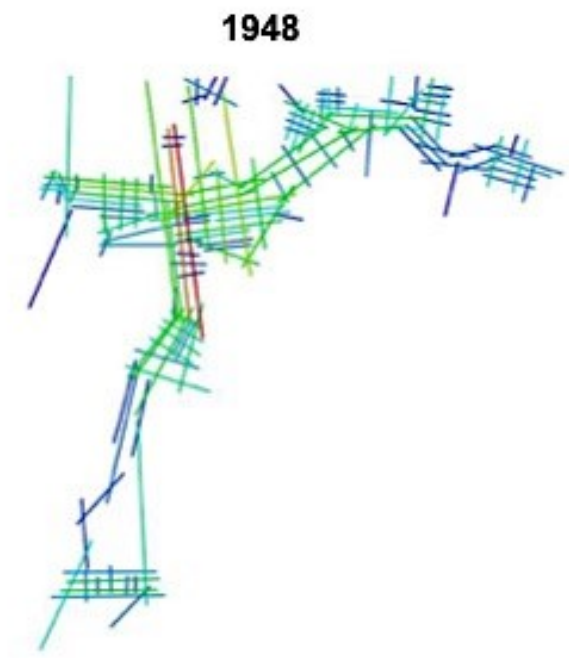

Fonte: original dos autores, 2016

Na análise comparativa entre os anos de 1990 e 2016 (Fig. 6), a via com maior conexão viária passou a ser a Rua Ícaro, via esta com grande extensão, e principal rota de acesso a cidade vizinha de Campo Bom. O perfil das edificações dispostas ao longo dessa via é composto por residências de médio padrão construtivo, condomínios residenciais populares, fábricas, indústrias, comércio e serviços, além de praças e áreas de lazer, ou seja, todas as atividades necessárias à vida urbana são contempladas. Desse modo, é possível que a Ícaro tenha atrativos suficientes para que as pessoas escolham essa rua como rota frequente de deslocamento. 
Figura 6. Concectividade nos anos de 1990 e 2016

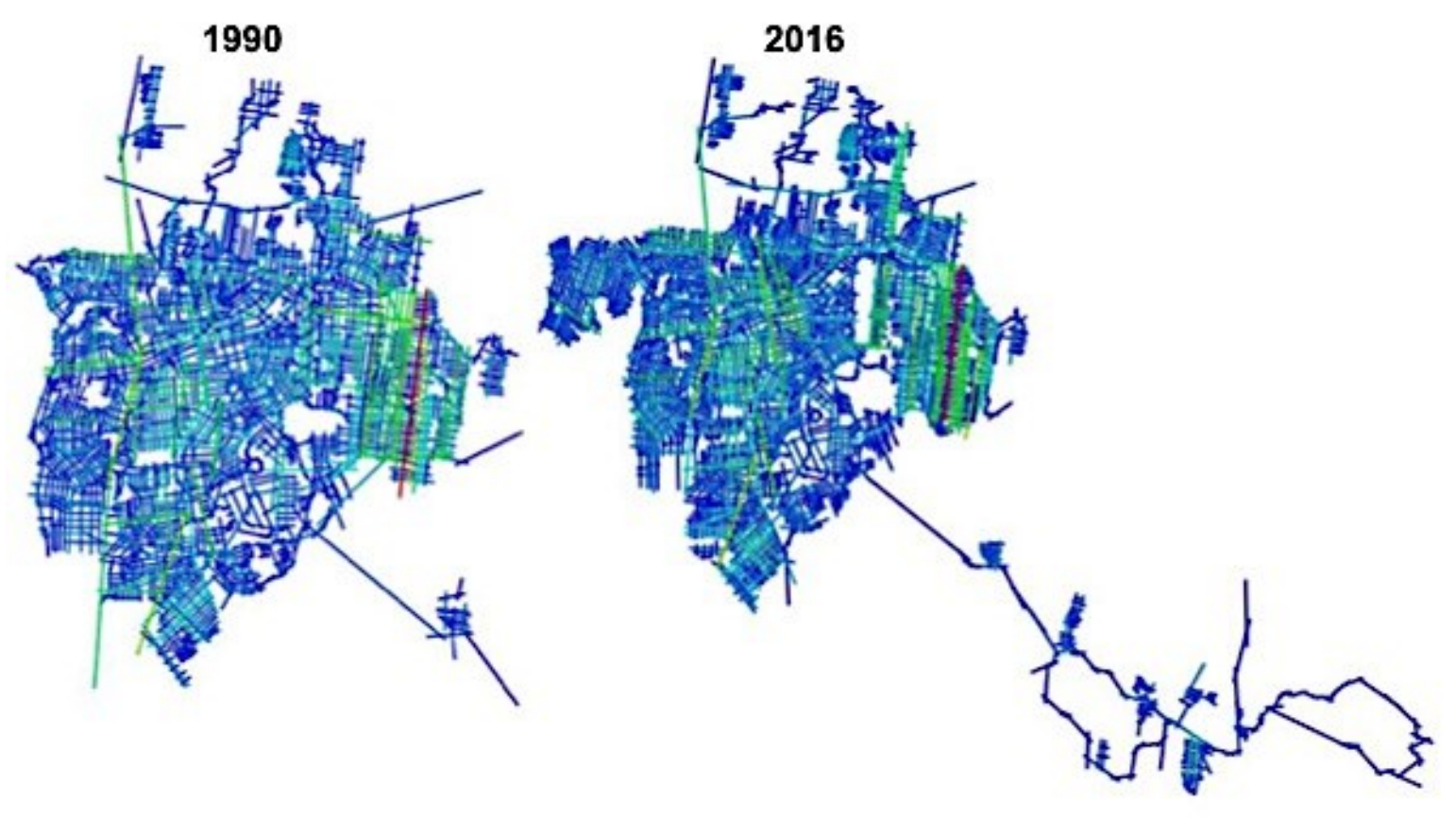

Fonte: original dos autores, 2016

Quanto ao nível de distanciamento e segregação das linhas axiais em relação a área central (profundidade do sistema de vias) esta foi medida para os dois percursos (o da antiga linha férrea, seguindo ao longo de toda a Avenida Primeiro de Março) e o do trajeto do trem em atividade atualmente (que altera o percurso a partir da bifurcação com a Rua Nações Unidas). Ambas as análises foram feitas com base no mapa viário atual - de 2016. Cada trecho do percurso, de ambos os trajetos, foi demarcado com uma linha axial de coloração preta, para que seja possível perceber esse indicador de análise por fragmento de via (Fig. 7). 


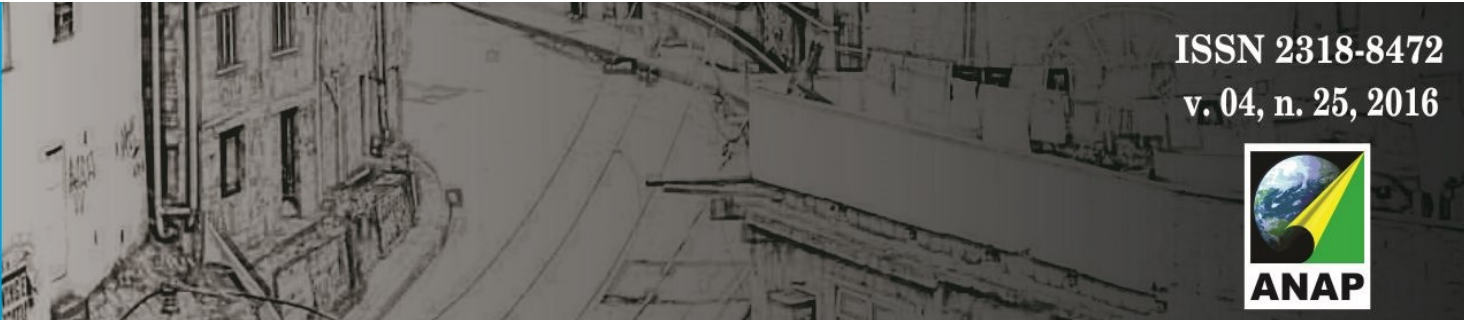

Gerenciamento de Cidades

\section{CONSIDERAÇÕES FINAIS}

Percebe-se que a evolução urbana do sistema de vias de Novo Hamburgo iniciou com a antiga linha férrea e entorno do trajeto percorrido pelo trem. Estabelecimentos de comércio e serviços atraídos pela possibilidade de deslocamento de mercadorias que a ferrovia tinha a oferecer, bem como pelo alto fluxo de pessoas em trânsito, corroboraram para a formação da zona central da cidade.

No mapa de 1948, é possível ver a cidade e suas conexões viárias ao longo da linha, mas também um crescimento direcionado a outras vias principais de deslocamento, com crescente importância na mobilidade urbana, ou seja, a atual BR-116 e a RS-239, interligando a cidade à capital e demais cidades do país e do estado.

Desse modo, os mapas axiais apresentados indicam que, primeiramente, a expansão urbana de Novo Hamburgo esteve diretamente relacionada ao incremento da acessibilidade e mobilidade urbana. No entanto, a partir do mapa de 1990, percebe-se a expansão radial entorno do centro e, assim, considera-se como fator de atratividade o tipo de estabelecimento encontrado nessa área - demonstrado pelos mapas axiais de conectividade, que indicam uma via nos limites urbanos da cidade como a mais conectada ao sistema de vias.

Portanto, a relação do transporte ferroviário com a cidade de Novo Hamburgo esteve mais presente quando da implementação da primeira linha férrea da cidade (quando influenciou o traçado do sistema de vias) do que nos dias atuais, e após a inauguração da linha da Trensurb, em 2014.

Os vazios urbanos localizados a longo da linha da Trensurb em Novo Hamburgo, são uma consequência tanto da ausência de espaços com atividades variadas e de espaços públicos acessíveis à todos, quanto do nível de acessibilidade do sistema de vias. Ou seja, a existência de vazios urbanos sob a estrutura do trem está relacionada à (i) falta de atrativos para encontro de pessoas e de atividades necessárias ao dia-a-dia na cidade (como comércio e serviços); ao (ii) sistema de vias de Novo Hamburgo; e a (iii) alteração do trajeto ferroviário implementado em 2014, em relação ao extinto em 1966. Com a possibilidade de novos usos das áreas remanescentes e, consequente aumento do movimento de pessoas, novos fluxos poderão ser criados, observando-se o interesse da população em percorrer a via onde o trem está inserido. 


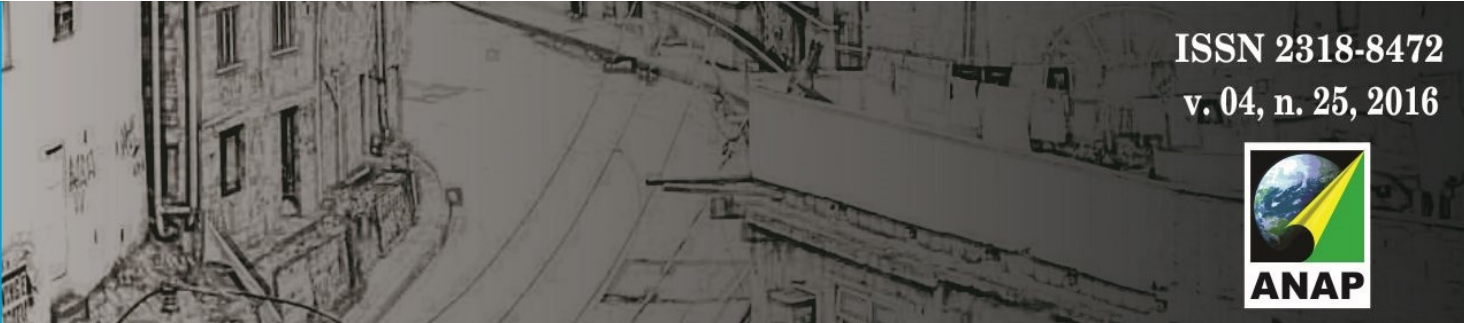

\section{REFERÊNCIAS}

ALVES, Glória da Anunciação. A mobilidade/imobilidade na produção do espaço urbano. In: Diversos autores. A produção do espaço urbano: agentes e processos, escalas e desafios. Ana Fani Alessandri Carlos; Marcelo Lopes de Souza; Maria Encarnação Beltrão Sposito (organizadores), 1.ed. São Paulo: Contexto, 2014.

BRAUN, Felipe Kuhn. História da imigração alemã no sul do Brasil. Porto Alegre: Costoli Soluções Gráficas, 2010.

CARMO, Cássio Leandro do; RAIA JÚNIOR, Archimedes Azevedo \& NOGUEIRA, Adriana Dantas. Aplicações da sintaxe espacial no planejamento da mobilidade urbana. Revista Ciência \& Engenharia, junho de 2013. Disponível em: http://www.seer.ufu.br/index.php/cieng/article/viewFile/22874/13672. Acesso em 29 jul. 2016.

FIGUEIREDO, Lucas. Mindwalk 1.0: Space Syntax Software. Laboratório de Estudos Avançados de Arquitetura - LA. Pernambuco: Universidade Feral de pernambuco, 2005. Disponível em: https://pt.scribd.com/doc/315392207/Manual-Mindwalk-Space-Syntax-Software-Portuguese-pdf. Acesso em 30 jul. 2016.

GAUDIN, Jean-Pierre. Desenho e futuro das cidades.: uma antologia. Tradução de Estela dos Santos Abreu e Waleska Moysés. 1 ed. Rio de Janeiro: Rio Book's, 2014.

HILLIER, Bill; LEAMAN, STANSALL, Paul; BEDFORD, Michael. Sintaxe do Espaço.Tradução de Diogenes Falcão pereira e Edja Trigueiro. Revista Thésis, n.1, janeiro/junho de 2016. Disponível em:http://anparq.web965.uni5.net/index.php/revista-thesis/article/view/10. Acesso em 30 jul. 2016.

JALES, Antônio Wagner Lopes. Os impactos urbanos de uma intervenção viária: avaliação da implantação da Via Expressa em São Luis usando a Sintaxe Espacial. Arquitextos, São Paulo, ano 15, n. 171.02, ago. 2014, disponível em: http://www.vitruvius.com.br/revistas/read/arquitextos/15.171/5289. Acesso em 31 jul. 2016.

RIBEIRO, Manoela Souza \& MEDEIROS, Valério Augusto Soares de. A regularidade dos padrões urbanos: a sintaxe espacial como estratégia para leitura de Olinda e Brasília. Revista Oculum Ensaios, n.16, Campinas ,2012. Disponível em http://periodicos.puccampinas.edu.br/seer/index.php/oculum/article/view/1456/1430.Acesso em 27 jul. 2016.

PANERAI, Philippe; CASTEX, Jean \& DEPAULE, Jean-charles.Formas urbanas: a dissolução da quadra. Tradução de Alexandre Salvaterra. Porto Alegre: Bookmann, 2013.

SCHUTZ, Liene M. Martins. Novo Hamburgo: sua história, sua gente. Porto Alegre: Palotti, 1992.

SELBACH, Jeferson Francisco. Pegadas urbanas: Novo Hamburgo como palco do flâneur. Cachoeira do Sul: Ed. do Autor, 2006. Disponível em: http://www.dominiopublico.gov.br/download/texto/ea000077.pdf. Acesso em 06 jul. 2016.

SERPA, Ângelo.Lugar e centralidade em um contexto metropolitano. In: Diversos autores. A produção do espaço urbano: agentes e processos, escalas e desafios. Ana Fani Alessandri Carlos; Marcelo Lopes de Souza; Maria Encarnação Beltrão Sposito (organizadores), 1.ed. São Paulo: Contexto, 2014.

VARGAS, Heliana Comim \& CASTILHO, Ana Luisa Howard.Intervenções em centros urbanos: objetivos, estratégias e resultados. 3 ed. Barueri: Manole, 2015. 
